\title{
Spontaneous Resolution of Traumatic AV Malformation of the Uterus Following Hysteroscopic Cold Knife Evacuation of Retained Products of Conception
}

\author{
Divyesh V. Shukla*, Shilpi D. Shukla, Amit Shah, Sangita Patel, Vaidehi Nene \\ Isha Hospital, Sarabhai Campus, Vadodara, India \\ Email: *divyeshshukla@yahoo.com
}

How to cite this paper: Shukla, D.V., Shukla, S.D., Shah, A., Patel, S. and Nene, V. (2020) Spontaneous Resolution of Traumatic AV Malformation of the Uterus Following Hysteroscopic Cold Knife Evacuation of Retained Products of Conception. Open Journal of Obstetrics and Gynecology, 10, 790-801.

https://doi.org/10.4236/ojog.2020.1060073

Received: May 4, 2020

Accepted: June 9, 2020

Published: June 11, 2020

Copyright $\odot 2020$ by author(s) and Scientific Research Publishing Inc. This work is licensed under the Creative Commons Attribution International License (CC BY 4.0).

http://creativecommons.org/licenses/by/4.0/ (c) (i) Open Access

\begin{abstract}
Uterine myometrial arteriovenous malformations (AVM) are reported on color doppler ultrasonography as mosaic pattern of blood flow with different peak systolic velocities (PSV) at different places. High PSV within the AVM may require arterial embolization as treatment. However, we present a case of traumatic AVM with incomplete abortion managed by hysteroscopic cold knife evacuation. This case report is of a young patient with off and on vaginal bleeding for $31 / 2$ months following $2^{\text {nd }}$ trimester spontaneous abortion. She had undergone dilation and evacuation (D \& E) for incomplete abortion. Now the bleeding was heavy and intermittent not responding to medications. The subsequent TVS examination shows incomplete abortion with myometrial AVM with high PSV. Hysteroscopic cold knife removal of products of conception resulted in immediate resolution of Uterine AVM.
\end{abstract}

\section{Keywords}

AVM, Color Doppler, Cold Knife Evacuation, D \& E, Hysteroscopy, Retained Products, Uterus, PSV

\section{Introduction}

Uterine myometrial AVM are reported on color doppler ultrasonography. They also are mentioned as enhanced myometrial vascularity, especially in post-partum period. These are rare tangled mass like conglomerate between artery and vein without interposition of capillary connection. They can be congenital or acquired. Congenital AVM are because of faulty angiogenesis. AVM can lead to tissue damage because of improper oxygenation. Bleeding may occur from these 
$\mathrm{AV}$ malformations as the thin wall of these vessels gets disrupted because of hormonal effect or surgical trauma [1]. The bleeding pattern is not predictive and is intermittent to massive blood loss not responsive to medical treatment. Acquired malformations can be because of surgical uterine trauma or because of preexisting pathology [2] [3]. Uterine myometrial AVM can be found alone or they are associated with retained products in uterine cavity [4]. AVM are also reported in the retained products within the uterine cavity [5].

Published case reports and case series described uterine artery embolization (UAE) as method of treatment used in patients with uterine AVM with high PSV on color doppler USG. D \& E may or may not be for retained products after this procedure. In this case report of uterine AVM with high PSV, successful treatment was achieved without UAE.

\section{Case Report}

An international patient had presented 1 year back with bleeding off and on for $31 / 2$ months following spontaneous abortion at 18 weeks of pregnancy. On day 4 of spontaneous abortion she was prescribed antibiotics and antipyretics for fever. Details of these medications were not available. D \& E was done under anaesthesia for incomplete abortion as patient continued bleeding. Following this procedure bleeding pattern became intermittently heavy.

She presented to us after 15 days of D \& E. Her obstetric history was Gravida 1 Abortion 1 and was married for 1 year. Her past menstrual history was normal. Her vital signs and cardiorespiratory system were normal. On per speculum examination at external OS of cervix products of conception of about $6 \mathrm{~mm}$ were seen, no vaginal discharge or bleeding was present. On per vaginal examination about $10 \mathrm{~mm}$ size overall products removed from partially dilated cervix. Bimanual palpation of uterus was of 6 - 8 weeks pregnant uterine size firm in consistency. No tenderness was observed in vaginal fornix. Products were sent for H-P examination.

Trans vaginal Ultrasound (TVS) was performed in the OPD. The uterus was retroverted enlarged. Mixed ecogenic products of conception of $24 \mathrm{~mm}$ size were present in cavity attached to anterior wall of uterus. At the same place in anterior wall of myometrium about $17 \times 14 \times 10 \mathrm{~mm}$ irregular tubular hypoechoeic area was seen extending up to junctional zone (Figures 1-3).

On color doppler examination this area was AVM visualized as having mosaic color pattern area (aliasing turbulent). The Resistance index (RI) observed was 0.10 - 0.33, Peak systolic velocity (PSV) was $92-105 \mathrm{~cm} / \mathrm{sec}$. Communication of AVM with left uterine artery could be traced. For more accurate results PSV measurements were done at 5 places and sample window was kept $2 \mathrm{~mm}$. Associated prominent peripheral myometrial vascularity was evident. No AVM was seen in products of conception in uterine cavity (Figures 4-6). Three $8 \mathrm{~mm}$ fibroid was seen in myometrium at FIGO type 5 location.

Clinical examination and TVS USG were suggestive of retained products with 


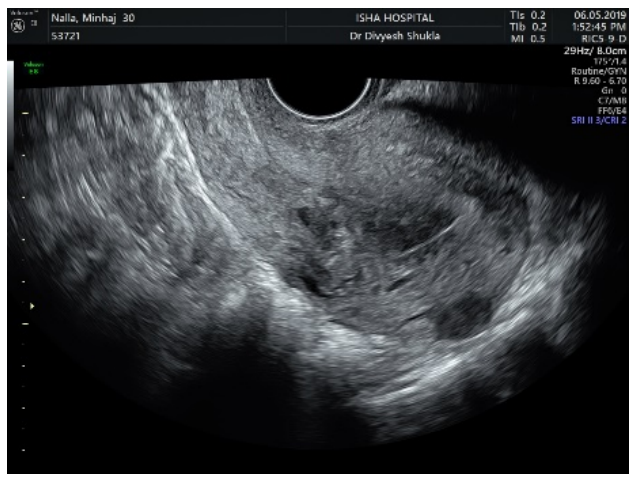

Figure 1. Anterior wall hypoechoeic area.

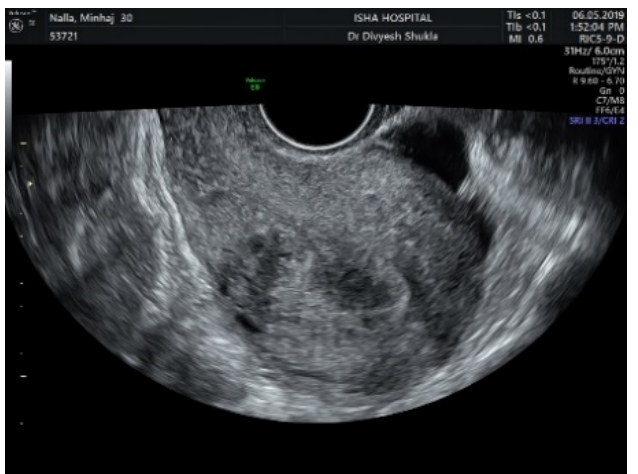

Figure 2. Anterior wall hypoechoeic area extending upto JZ.

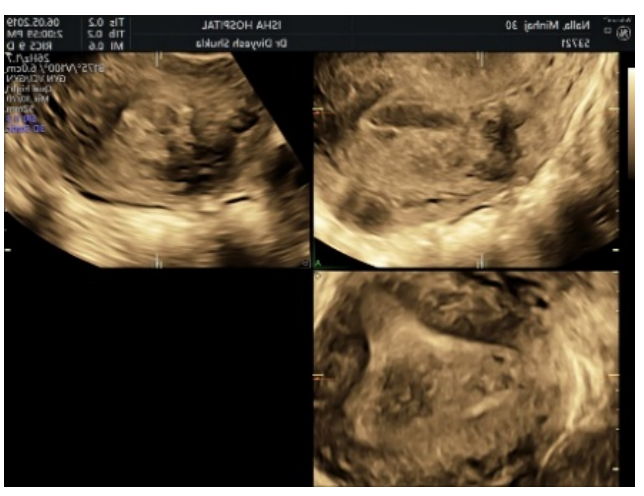

Figure 3. 3D image of AV lesion.

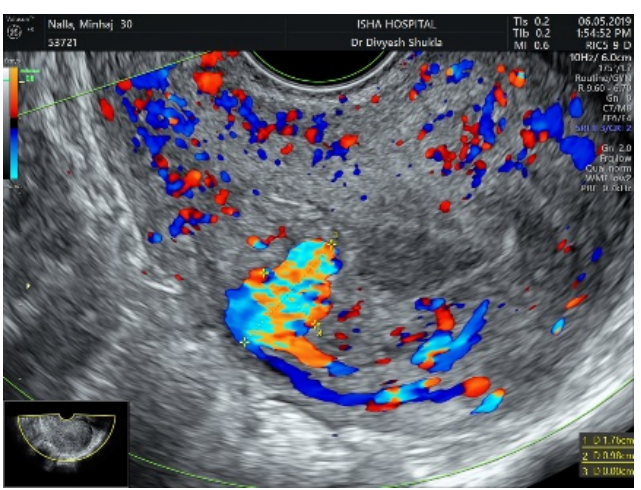

Figure 4. Mosaic blood flow in AV malformation. 


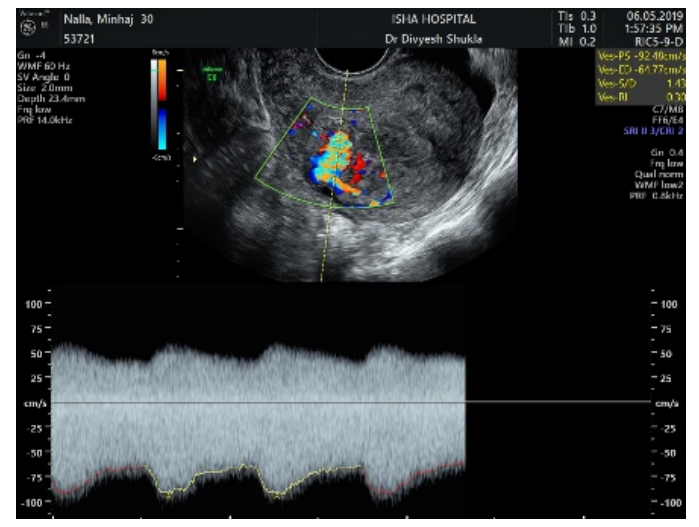

Figure 5. PSV in AV malformation $(92 \mathrm{~cm} / \mathrm{sec})$.

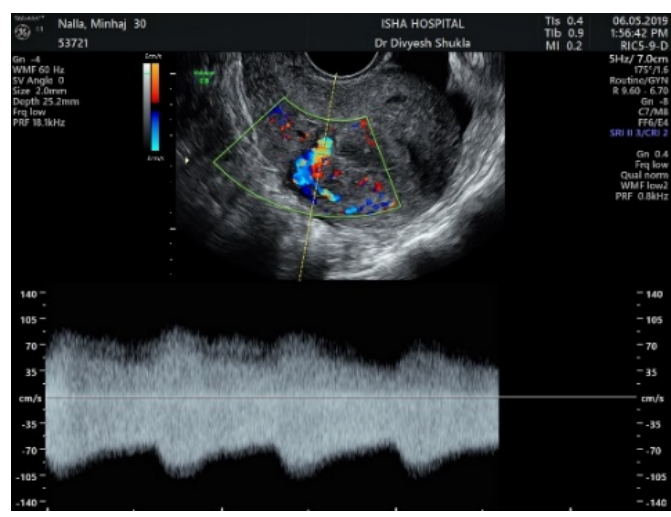

Figure 6. PSV in AV malformation $(105 \mathrm{~cm} / \mathrm{sec})$.

acquired uterine AVM having high PSV values. The AVM was secondary to uterine trauma following D \& E.

Her pre-operative investigations were normal as Haemoglobin: $11.9 \mathrm{gm} \%$, TC: 8930/cu mm, Blood group: O Positive, INR: 0.98, Platelet count: $2.98 / \mathrm{cu} \mathrm{mm}$, S.Creatinine: $0.50 \mathrm{mg} / \mathrm{dl}$, S.TSH: $4.280 \mathrm{mU} / \mathrm{L}$, HIV: Negative, HbsAg: Negative, SGPT: 29 u/L, Urine: Blood-+++, Esterase+++, Pus cells-30 - 40/hpf, RBC-90 100/hpf, EC-5 - 6 INR:, S. Beta HCG: <2.0 IU, RBS-92 mg/dl, Uric Acid-5 mg/dl, Urea-11.50 mg/dl, BUN-5.37.

Patient was scheduled for hysteroscopic cold knife evacuation of products after 24 hrs. of admission. Blood transfusions were kept ready. Patient was given amoxycillin clavulanic acid preparation $1.2 \mathrm{gm}$ intravenously $12 \mathrm{hr}$. for 2 doses as prophylaxis which was continued in the postoperative period as $625 \mathrm{mg}$ bd for total 7 days. Hysteroscopic surgery was performed by using 22 fr. bipolar resectoscope of Karl Storz make with bipolar loop electrode of $5 \mathrm{~mm}$. Endomat was used as continuous suction irrigation system using normal saline as distension media. Uterine cavity had retained products attached to, anterior and left lateral wall from cornual region to internal OS. Both cornual area and rest uterine cavity had normal endometrium (Figures 7-9).

Complete evacuation of visible retained products was done with the use of bipolar cold loop electrode (Figure 10, Figure 11). Anteriorly immediately 


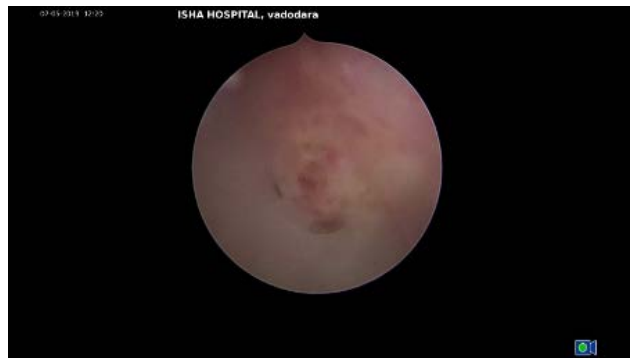

Figure 7. Retained products left wall.

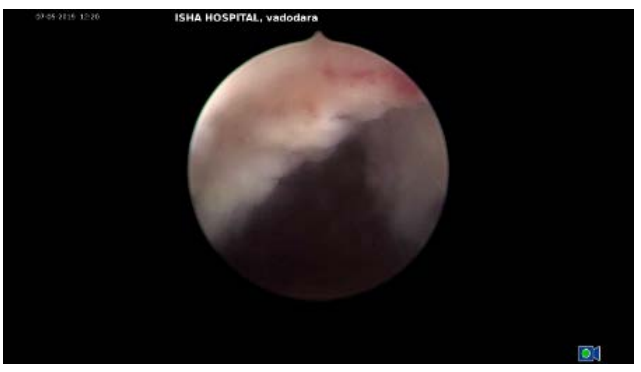

Figure 8. Retained products above internal OS anterior.

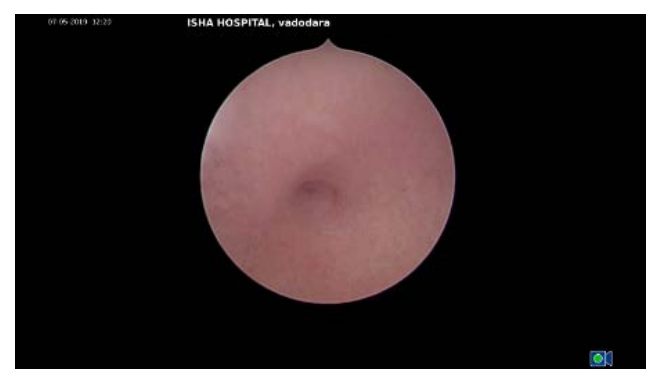

Figure 9. Normal cornu right.

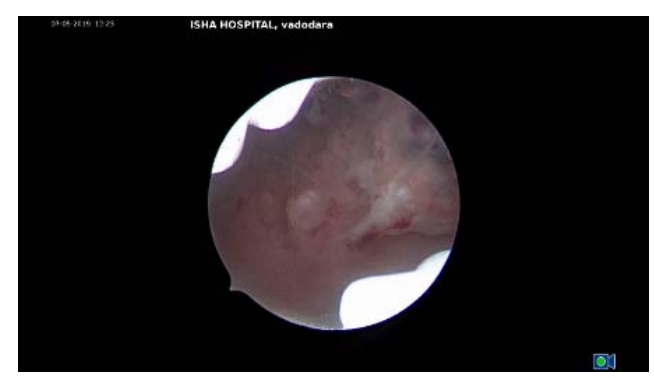

Figure 10. Cold knife removal of products.

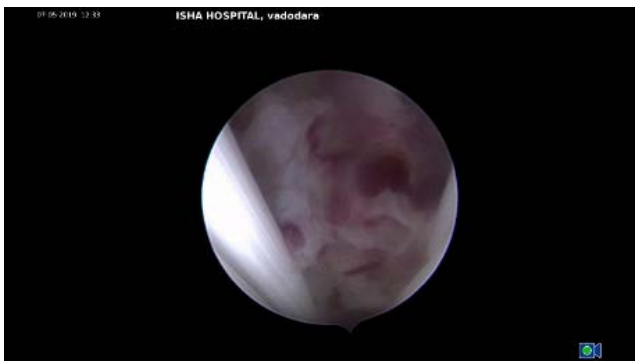

Figure 11. Cold knife removal of products. 
above internal OS on removal of adherent products a depression was evident (15 $\times 15 \times 5 \mathrm{~mm}$ ). This indicated past uterine trauma. This was the area on USG where AVM had touched junctional zone (JZ). Significant bleeding was seen from open vessels in this area after removing products (Figure 12, Figure 13).

Bipolar loop with coagulation current was used for coagulation of multiple bleeding vessels at this place to stop bleeding.

Minimal active bleeding was seen through external OS of the cervix on withdrawing resectoscope (Figure 14). Immediately bimanual compression of uterus especially portion of uterus just above internal OS was performed for $10 \mathrm{~min}$. No active bleeding was observed after compression. Intra-operative USG confirmed complete evacuation and resolution of AVM (Figures 15-17).

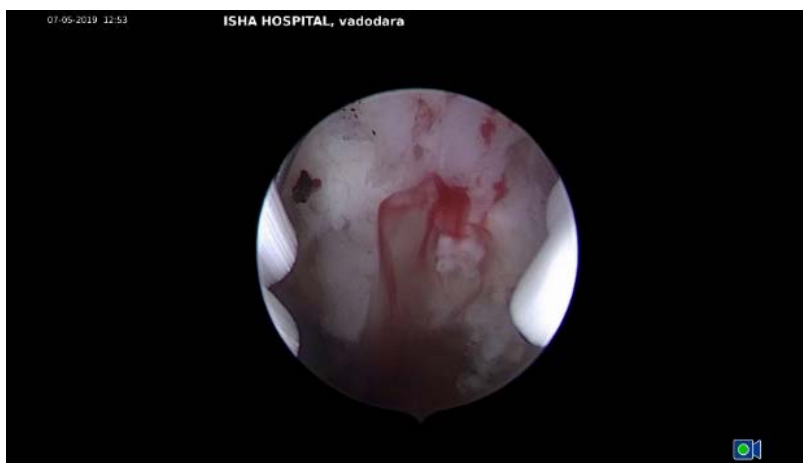

Figure 12. Haemostasis by bipolar loop.

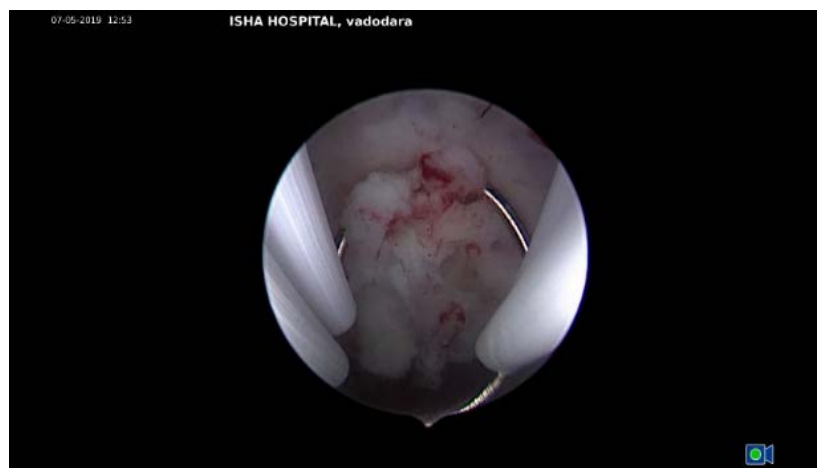

Figure 13. Haemostasis by bipolar loop.

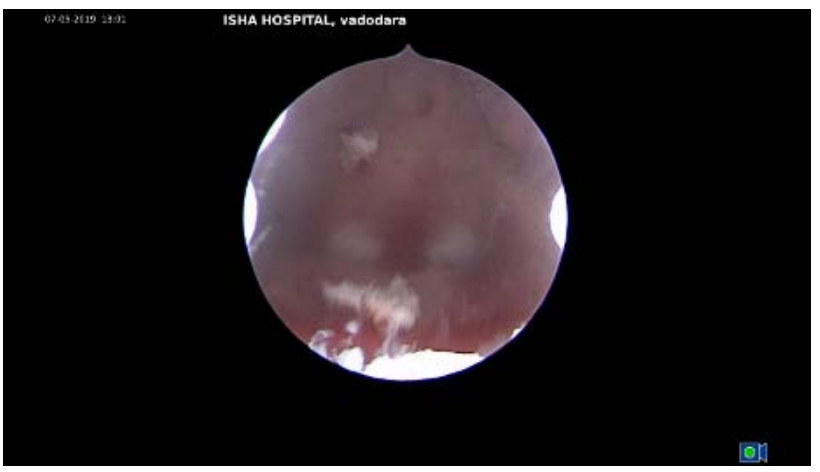

Figure 14. Complete evacuation with haemostasis with floating removed products. 


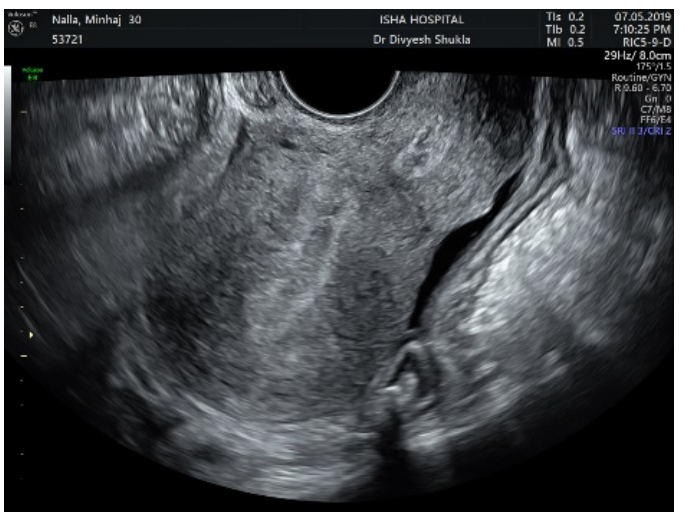

Figure 15. Resolution of AV malformation anterior wall.

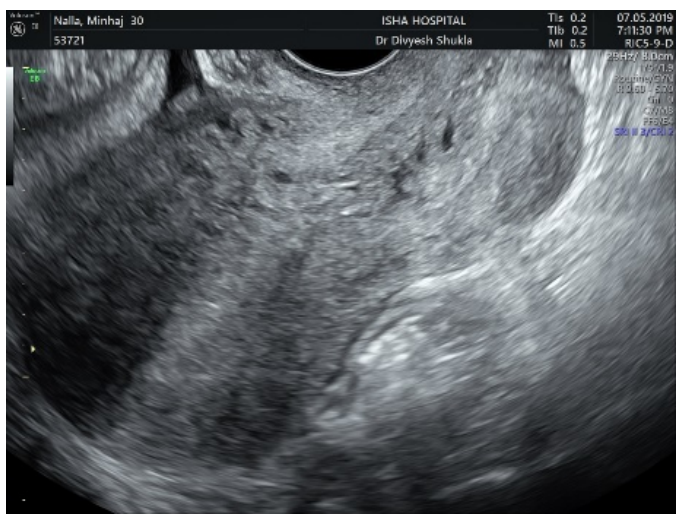

Figure 16. Resolution of AV malformation anterior wall.

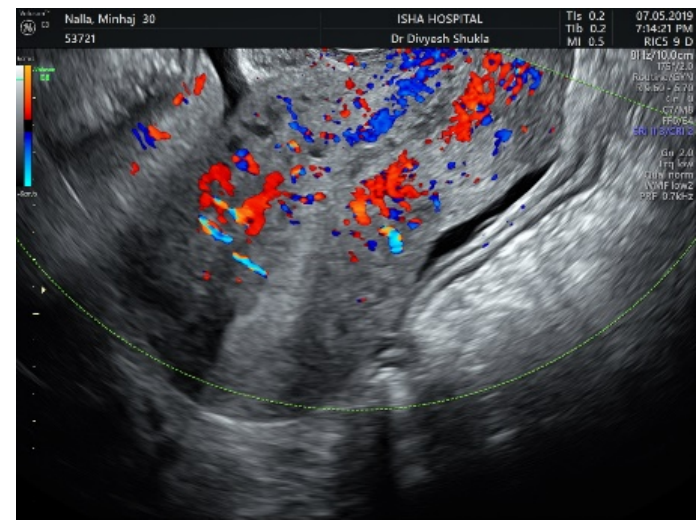

Figure 17. Normal myometrial color doppler blood flow.

No deficit of normal saline was observed at the end of procedure. Intraoperative blood loss estimated was about $25 \mathrm{cc}$. Patient was given analgesics for 2 days and antibiotics were continued for 7 days. She also was given injection Leupride acetate $3.75 \mathrm{mg}$ intramuscular as she wanted to travel back and avoid bleeding.

Patient was discharged from the hospital after $24 \mathrm{hrs}$. of stay. There were no immediate or delayed post-operative complications. The histopathological examination of removed/evacuated products was consistent with retained placental tissue. 
Follow up after 7 days and at the end of $6^{\text {th }}$ week was uneventful.

\section{Discussion}

Acquired uterine AV malformations are rare. The incidence reported after delivery or abortion is $0.24 \%-0.63 \%$ [6] [7]. The term enhanced myometrial vascularity could be a normal finding in early post-partum period located at placental site which subsequently disappears by 6 wks. They can be present as focal area to large area of hypervascularity in $8.3 \%$ cases. Enhanced vascularity is presence of marked flow in full thickness of myometrium reaching cavity [8]. A lower pulsatility and a higher maximal flow velocity in the uterine arteries confirm EMV as a distinct entity [9]. However Ilan E and Timor-Tritsch in 2015 and 2016 had used term uterine AVM and EMV interchangeably [10] [11]. These types of AVM have a single arteriovenous communication between the branches of the uterine artery and the myometrial venous plexus [12].

In this patient of AVM with bleeding, TVS ultrasound had revealed about 17 $\times 14 \times 10 \mathrm{~mm}$ size AVM in anterior uterine wall reaching JZ. Aliasing was observed within the AVM because of turbulence with high velocities. The Peak systolic velocity measurements of AVM in this patient were ranging from 92 $105 \mathrm{~cm} / \mathrm{sec}$. averaging $96.2 \mathrm{~cm} / \mathrm{sec}$. The sample window was adjusted $2 \mathrm{~mm}$ and without changing angle of insonation and the velocity calculations were made at 5 different areas to have more accurate velocity measurement. The current patient falls in the category of high risk as the PSV on average was $96.2 \mathrm{~cm} / \mathrm{sec}$. And when the PSV is $>83 \mathrm{~cm} / \mathrm{sec}$ there are higher probabilities for embolization procedure requirement for treatment [1] [3] [6] [13] [14] [15].

There are some studies recommending UAE procedure before attempting intrauterine procedure as $\mathrm{D} \& \mathrm{E}$ for bleeding and retained products in these circumstances where the observed value of PSV of AVM is $>83 \mathrm{~cm} / \mathrm{sec}$ [11].

Same studies have expressed that no vascular embolization procedure was required when AVM PSV was $<39 \mathrm{~cm} / \mathrm{sec}$. In these patients D \& E can be safely performed without the risk of haemorrhage.

In cases of heavy bleeding with Uterine AVM following abortion or delivery unilateral or bilateral uterine artery embolization (UAE) procedure is a safe procedure but can sometimes compromise future fertility and increase pregnancy complications. This procedure is successful to stop bleeding in $>90 \%$ cases [12] [16] [17]. Some patients may require 2 or 3 embolization procedures to stop bleeding [11].

Spontaneous resolution or expulsion of retained products of conception has been documented following UAE procedure.

As majority of the patients having AVM's are in reproductive age, the management plan should include maximum preservation of future fertility.

The patients having incomplete abortion with AVM there are three options other than UAE. A blind D \& E or D \& E under USG guidance or hysteroscopic evacuation of products of conception. 
In the present case despite of having PSV values recorded as high as 105 $\mathrm{cm} / \mathrm{sec}$ hysteroscopic cold knife evacuation of products of conception by using bipolar resectoscope loop (22 fr Bipolar resectoscope Karl Storz made) was planned. Hysteroscopy should be considered as highly effective visual procedure to treat incomplete abortion better than USG guided D \& E or blind D \& $\mathrm{E}$. There are other advantages, we leave no chance of incomplete evacuation, additional trauma to the uterine cavity is avoided, using bipolar loop electrode helps in coagulation of opened vessels to reduce or stop the bleeding. Such hysteroscopic procedure will never compromise her future fertility.

In this patient $\mathrm{D} \& \mathrm{E}$ performed 15 days before had resulted in uterine trauma and incomplete evacuation which was evident on hysteroscopy.

Some published hysteroscopic studies have described along with removal of products, hysteroscopic excision of AV malformation area. This was reflected from the histopathology details of the specimen mentioned [18]. We do not recommend any such myometrial excision (containing AV malformation) which can affect future fertility. Some studies have mentioned hysteroscopy to diagnose AV malformations within products of conception and subsequent treatment by uterine artery embolization [19].

Hysteroscopic cold knife evacuation is a standard practice in our hospital to treat patients of incomplete abortion presenting with irregular prolonged bleeding and late diagnosis.

In this patient immediate resolution of AVM was noticed following evacuation of products which was documented by performing TVS intra and postoperatively.

Resolution of uterine AVM was seen after medical treatment with GnRh analogues especially in absence of retained products and PSV values $<39 \mathrm{~cm} / \mathrm{sec}$ [20]. There are published case reports with conservative treatment of Uterine AVM with elevated beta HCG levels. The lesions disappear with response to decline in Hcg levels [21]. The study does not mention which conservative treatment was offered to the reported cases.

In patients who may not want to preserve future fertility case reports have been published where they have been offered hysterectomy as treatment for bleeding because of acquired AV malformations [22].

The acquired AVM's should be differentiated from AVM's associated with uterine pathological conditions as trophoblastic disease, sarcoma, hemangioma, varicose veins etc. In this condition the lesions are not pulsatile. The location of the lesion may differ.

\section{Conclusion}

Intermittent heavy bleeding is associated with acquired uterine AVM which requires urgent attention. Majority of patients have history of myometrial injury (D \& E, puerperal curettage, cesarean section, myomectomy, etc.). Color doppler study measuring PSV's studies helps in deciding mode of treatment. Patients 
with incomplete abortion having AVM with peak systolic velocities $>83 \mathrm{~cm} / \mathrm{sec}$ may be offered hysteroscopic cold knife evacuation. Chances that patient would respond to stop bleeding are high as complete evacuation and haemostasis can be ensured. Spontaneous resolution of AVM can be expected in these patients with cure of bleeding problem. UAE may not be required despite of high PSV values.

\section{Learning Points}

Uterine AVM should be suspected in patients presenting with persistent heavy bleeding following abortion or during puerperium presenting with secondary post-partum haemorrhage not responding to medical treatment.

Treatment of Uterine AVM's can be conservative medical, conservative surgical, unilateral, or bilateral UAE or if a patient does not want to preserve fertility, hysterectomy may be offered.

\section{Conflicts of Interest}

There was no conflict of interest \& due consent of the patient was taken to report her clinical case.

\section{References}

[1] Kim, T., et al. (2014) Management of Bleeding Uterine Arteriovenous Malformation with Bilateral uterine Artery Embolization. Yonsei Medical Journal, 55, 367-373. https://doi.org/10.3349/ymj.2014.55.2.367

[2] Yang, J.J., Xiang, Y., Wan, X.R. and Yang, X.Y. (2005) Diagnosis and Management of Uterine Arteriovenous Fistulas with Massive Vaginal Bleeding. International Journal of Gynecology \& Obstetrics, 89, 114-119. https://doi.org/10.1016/j.ijgo.2004.11.037

[3] Maleux, G., Timmerman, D., Heye, S. and Wilms, G. (2006) Acquired Uterine Vascular Malformations: Radiological and Clinical Outcome after Transcatheter Embolotherapy. European Radiology, 16, 299-306. https://doi.org/10.1007/s00330-005-2799-5

[4] Aziz, N., Lenzi, T.A., Jeffrey, R.B. and Lyell, D.J. (2004) Postpartum Uterine Arteriovenous Fistula. Obstetrics \& Gynecology, 103, 1076-1078. https://doi.org/10.1097/01.AOG.0000123241.44401.01

[5] Jain, K. and Fogata, M. (2007) Retained Products of Conception Mimicking a Large Endometrial AVM: Complete Resolution Following Spontaneous Abortion. Journal of Clinical Ultrasound, 35, 42-47. https://doi.org/10.1002/jcu.20250

[6] Yazawa, H., et al. (2013) Prospective Evaluation of the Incidence of Uterine Vascular Malformations Developing after Abortion or Delivery. Journal of Minimally Invasive Gynecology, 20, 360-367. https://doi.org/10.1016/j.jmig.2012.12.008

[7] Katimada Annaiah, T. and Kodakkattil Sreenivasan, S. (2015) Uterine Arteriovenous Malformations: Clinical Implications. Obstetrics and Gynaecology, 17, 243-250. https://doi.org/10.1111/tog.12218

[8] Van Den Bosch, T., Van Schoubroeck, D., Lu, C., De Brabanter, J., Van Huffel, S. and Timmerman, D. (2002) Color Doppler and Gray-Scale Ultrasound Evaluation 
of the Postpartum Uterus. Ultrasound Obstetrics \& Gynecology, 20, 586-591. https://doi.org/10.1046/j.1469-0705.2002.00851.x

[9] Van Schoubroeck, D., Van Den Bosch, T., Scharpe, K., Lu, C., Van Huffel, S. and Timmerman, D. (2004) Prospective Evaluation of Blood Flow in the Myometrium and Uterine Arteries in the Puerperium. Ultrasound Obstetrics \& Gynecology, 23, 378-381. https://doi.org/10.1002/uog.963

[10] Timor-Tritsch, I.E., Haynes, M.C., Monteagudo, A., Khatib, N. and Kovács, S. (2016) Ultrasound Diagnosis and Management of Acquired Uterine Enhanced Myometrial Vascularity/Arteriovenous Malformations. American Journal of Obstetrics \& Gynecology, 214, 731.e1-731.e10. https://doi.org/10.1016/j.ajog.2015.12.024

[11] Zhu, Y.P., Sun, Z.J., Lang, J.H. and Pan, J. (2018) Clinical Characteristic and Management of Acquired Uterine Arteriovenous Malformation. Chinese Medical Journal, 131, 2489-2491. https://doi.org/10.4103/0366-6999.243570

[12] Yoon, D., Jones, M., Taani, J., Buhimschi, C. and Dowell, J. (2015) A Systematic Review of Acquired Uterine Arteriovenous Malformations: Pathophysiology, Diagnosis, and Transcatheter Treatment. American Journal of Perinatology Reports, 6, e6-e14. https://doi.org/10.1055/s-0035-1563721

[13] Timmerman, D., et al. (2003) Color Doppler Imaging Is a Valuable Tool for the Diagnosis and Management of Uterine Vascular Malformations. Ultrasound Obstetrics \& Gynecology, 21, 570-577. https://doi.org/10.1002/uog.159

[14] Shilpa, D., Vidya, M., Meenakshi, D. and Shrenik, P. (2014) Catastrophic Post Cesarean Bleeding Due to Arteriovenous Malformation: Case Report. Indian Journal of Basic and Applied Medical Research, 3, 654-657.

[15] Chen, Y., Wang, G., Xie, F., Wang, B., Tao, G. and Kong, B. (2013) Case Series Embolization of Uterine Arteriovenous Malformation.

[16] Tan, C.C.P., Tan, C.C.P., Mathur, M. and Lo, R.H.G. (2017) Uterine Arteriovenous Malformation: A Rare Cause of Secondary Postpartum Hemorrhage. Journal of Medical Cases, 8, 152-154. https://doi.org/10.14740/jmc2804w

[17] Cura, M., Martinez, N., Cura, A., Dalsaso, T.J. and Elmerhi, F. (2009) Arteriovenous Malformations of the Uterus. Acta Radiologica, 50, 823-829.

https://doi.org/10.1080/02841850903008792

[18] Calzolari, S., Cozzolino, M., Castellacci, E., Dubini, V., Farruggia, A. and Sisti, G. (2017) Hysteroscopic Management of Uterine Arteriovenous Malformation. Journal of the Society of Laparoendoscopic Surgeons, 21, e2016.00109. https://doi.org/10.4293/JSLS.2016.00109

[19] Chittawar, P., Patel, K., Agrawal, P. and Bhandari, S. (2013) Hysteroscopic Diagnosis and Successful Management of an Acquired Uterine Arteriovenous Malformation by Percutaneous Embolotherapy. Journal of Mid-Life Health, 4, 57. https://doi.org/10.4103/0976-7800.109641

[20] Vilos, A.G., Oraif, A., Machado, M., Abu-Rafea, B. and Vilos, G.A. (2019) Resolution of Uterine Arteriovenous Malformation and Maintenance of Reproduction in 20 Women Treated with a GnRH Agonist Concomitantly with an Aromatase Inhibitor and Tranexamic Acid. Journal of Obstetrics and Gynaecology Canada, 41, 772-781. https://doi.org/10.1016/j.jogc.2018.07.018

[21] Darlow, K.L., Horne, A.W., Critchley, H.O.D., Walker, J. and Colin Duncan, W. (2008) Management of Vascular Uterine Lesions Associated with Persistent Low-Level Human Chorionic Gonadotrophin. Journal of Family Planning and Reproductive Health Care, 34, 118-120. 
[22] Savelli, L. (2016) Acquired Uterine Arterovenous Malformation after Termination of Pregnancy: Sonographic-Pathologic Correlation and Description of Findings: A Case Report. Journal of Clinical Case Reports, 6, 2.

https://doi.org/10.4172/2165-7920.1000718 